\title{
Collagen I and III Ratios and Tenacity of Rats' Muscle Injured and Treated with Platelet-Rich Plasma
}

\author{
Relaciones de Colágeno I y III y Tenacidad del Músculo de \\ Rata Lesionado y Tratado con Plasma Rico en Plaquetas
}

\begin{abstract}
Thiago Alves Garcia ${ }^{1}$; Guilherme Akio Tamura Ozaki²; Robson Chacon Castoldi ${ }^{3}$; Aldo Eloizo Job ${ }^{4}$; Regina Celi Trindade Camargo ${ }^{5}$; José Carlos Silva Camargo Filho ${ }^{5}$ \& William Dias Belangero ${ }^{6}$
\end{abstract}

\begin{abstract}
GARCIA, T. A.; OZAKI, G. A. T.; CASTOLDI, R. C.; JOB, A. E.; CAMARGO, R. C. T.; FILHO, J. C. S. C. \& BELANGERO, W. D. Collagen I and III ratios and tenacity of rats' muscle injured and treated with platelet-rich plasma. Int. J. Morphol., 38(5):13921397,2020
\end{abstract}

SUMMARY: Severe muscle injuries are common in accidents and have a delayed recovery of muscle integrity. In these cases, muscle suture surgery is the standard treatment. However, Platelet Rich Plasma (PRP), has been widely used in orthopedic injuries due to its growth factors. Thus, the objective of the study will be to analyze the association of suture and PRP techniques in the collagen and tenacity of the injured muscle. Were used seventy rats, divided into five groups: control (C), injury control (CI), injury and suture (IS), injury and PRP (IP), injury, suture, and PRP (ISP). Were sectioned approximately $50 \%$ of the width and $100 \%$ of the thickness of the gastrocnemius muscle. The homologous PRP was applied $24 \mathrm{~h}$ after the injury. On the 7 th day after the injury, the animals were euthanized and their muscles subjected to mechanical testing to measure tenacity or collagen analysis to calculate the ratio between type I and III collagen. The results show a significant decrease $(\mathrm{p}<0.05)$ in the values of the relationship between collagens in all injured groups $(\mathrm{CI}$, IS, IP, ISP) compared to group C. In injured groups, the tenacity was significantly $(\mathrm{p}<0.05)$ reduced compared to the control group, with no observed difference between treatments and injured groups. The amount of collagen in the injured area has increased, but it did not affect the tenacity of the muscles, which was reduced.

KEY WORDS: Muscle injury; Platelet-rich plasma; Suture; Collagen.

\section{INTRODUCTION}

Muscle injuries are an important cause of sport or work absenteeism (Rui et al., 2013), these are commonly caused by very strong muscle contractions or accidents. Treatment depends on the extent, the broken structures and the number of broken fibers, these characteristics will define surgical or conservative treatment (Fernandes et al., 2015).

Severe muscle injuries, in which a large part of the muscle fibers are injured, are commonly treated by surgery, in this case, the edges of the ruptured muscle are united using absorbable or non-absorbable sutures (He et al., 2014; Horst et al., 2014; Ramos et al., 2015). The approximation of the ruptured edges creates a favorable environment for inflammation and afterward the muscle repair process, the sooner the muscle is repaired, the shorter the rehabilitation time and the absence of work. (Hwang et al., 2006).

In recent years, platelet-rich plasma (PRP) has been used frequently in several studies with musculoskeletal injuries (Willits et al., 2013). This method is performed with a blood sample that is centrifuged to concentrate the platelets, and applied to the focus of the injury (Hamid et al., 2014). Blood platelets have platelet-derived growth factor (PDGF), which stimulates the synthesis of components of the extracellular matrix and activation of satellite cells. In addition, it has beta transformation growth factor (TGF-b),

\footnotetext{
${ }^{1}$ Laboratório de Biomateriais (LABIMO), do Centro de Medicina Experimental e Cirurgia, Faculdade de Ciências Médicas, Universidade Estadual de Campinas, São Paulo, Brasil.

${ }^{2}$ Departamento de Fisioterapia, Universidade Estadual Paulista (UNIP), Campus Araçatuba, São Paulo, Brasil.

${ }^{3}$ Departamento de Educação Física, Universidade do Oeste Paulista, Campus Presidente Prudente, São Paulo, Brasil.

${ }^{4}$ Departamento de Física, Universidade Estadual Paulista "Júlio de Mesquita Filho", Campus Presidente Prudente, São Paulo, Brasil.

${ }^{5}$ Departamento de Fisioterapia, Universidade Estadual Paulista "Júlio de Mesquita Filho", Campus Presidente Prudente, São Paulo, Brasil.

${ }^{6}$ Departamento de Ortopedia e Traumatologia da Faculdade de Ciências Médicas da Universidade Estadual de Campinas, São Paulo, BrasiL.
} 
which stimulates fibroblast mitosis and type 1 insulin-like growth factor (IGF-1), which promotes myogenesis (Hammond et al., 2009; Cole et al., 2010; Sánchez-González et al., 2012). The release of these growth factors by the platelets within the focus of the injury can accelerate the repair process of the injured muscle, recovering its ability to receive external loads.

Regarding PRP in muscle injuries (Moraes et al., 2013: Andia \& Abate, 2015), no studies were found comparing or associating the PRP with the muscle suture technique. Thus, this study aims to compare the standard muscle suture technique associated or not with PRP through histology and mechanical testing of the injured and treated muscle.

\section{MATERIAL AND METHOD}

Animals. This research was approved by the ethics committee on the use of animals, from the Faculty of Science and Technology, FCT - Unesp, Presidente Prudente Campus, with protocol number: 01/2016.

We used 70 male rats with 150 days of Wistar lineage (Rattus norvegicus) obtained from the Universidade do Oeste Paulista (Unoeste) and kept in the bioterium of the Histology and Histochemistry Laboratory of the Faculty of Sciences and Technology of Presidente Prudente (FCT / UNESP) in collective boxes with water and feed provided ad libitum, with controlled conditions of temperature $\left(22{ }^{\circ} \mathrm{C} \pm 2\right)$, humidity $(50 \% \pm 10)$ and 12-hour light / dark cycle (7-19 h).

The animals were randomly allocated to five groups with 14 animals each. Control group (C): animals that did not receive the lesion or treatments, before being euthanized they had their blood punctured to prepare the PRP for the other groups; control injury group (CI): animals subjected to muscle injury; muscle injury and suture group (IS): animals that underwent muscle injury followed by muscle suture; muscle injury and PRP group (IP): animals subjected to muscle injury and application of PRP the day after the injury; muscle injury, suture, and PRP group (ISP): animals subjected to muscle injury followed by muscle suture surgery and application of PRP to the injury site the next day. All injured groups were euthanized 7 days after the injury.

Muscle Injury Protocol. The injured groups were anesthetized with an intraperitoneal injection of xylazine (15 $\mathrm{mg} / \mathrm{kg}$ ) and ketamine $(70 \mathrm{mg} / \mathrm{kg})$, after the confirmation of the anesthesia the gastrocnemius muscle of the right posterior paw was exposed through an incision and the muscle injury was performed with a scalpel, blade number 11 .
Approximately $50 \%$ of the width and $100 \%$ of the thickness was sectioned in the muscle largest diameter portion. This injury protocol was based on the study Hwang et al. In the IS and ISP groups, sutures of the animal's muscle planes and skin were performed, while in the CI and IP groups, only the animal's skin was sutured. The injured groups received analgesic drug tramadol hydrochloride (Tramal).

PRP preparation and application. The animals in group $\mathrm{C}$ were euthanized and their blood used to prepare the PRP applied in the other groups. Blood was collected by cardiac puncture using a syringe containing $2 \mathrm{ml}$ of $3.8 \%$ sodium citrate.

The blood was separated into $5 \mathrm{ml}$ tubes and centrifuged at $220 \mathrm{G}$ for 15 minutes, the buffy coat and serum component were transferred to another tube and centrifuged at $1270 \mathrm{G}$ for 5 minutes, the content at the bottom of the tube is the PRP (Li et al., 2012; Dimauro et al., 2014). In animals of the IP and ISP groups, $0.1 \mathrm{ml}$ of PRP was applied in the injured portion of the muscle using a sterile syringe. Some PRP samples were separated for platelet count.

Sampling. All animals were euthanized by intraperitoneal administration of an overdose of Xilasine $(140 \mathrm{mg} / \mathrm{kg})$ and Ketamine $(30 \mathrm{mg} / \mathrm{kg})$.

The muscles intended for the mechanical test were dissected, preserving their origin in the distal third of the femur and insertion in the calcaneus, after dissection, the muscles were kept in Ringer's lactate solution, at room temperature until the traction test was performed.

For histological analysis, the method of freezing nonfixed tissue was used. In this method, the muscles were immersed in a beaker containing 30 to $50 \mathrm{ml}$ of $\mathrm{N}$-hexane and this beaker was immersed in nitrogen. After the samples were frozen uniformly, they were stored at $-75^{\circ} \mathrm{C}$ in an ultra-low temperature freezer (CL580-80, Collab) until the preparation of the histological slides.

Transverse sections of the muscles with a thickness of $5 \mu \mathrm{m}$ were produced by means of a cryostat microtome (Microm, HM $505 \mathrm{E}$ ), at a temperature of $-20^{\circ} \mathrm{C}$. These were then stained by the Picrosirius red method for collagen analysis (Mescher, 2013). The analysis of the slides was performed using a polarized light microscope (Light LEICA DM 750), with a camera attached.

Histological analysis. Picrosirius staining observed under polarized light allows the differentiation of type I (red) and type III (green) collagen, using the Image J program the 
percentage of these collagens in relation to the total image area was measured. The ratio between the two was calculated by dividing the values of type I collagen by those of type III (Type I / III).

Mechanical test. The gastrocnemius of seven animals were used for the mechanical testing on the universal testing machine (EMIC®, model DL2000), equipped with a $50 \mathrm{~kg}$ load cell. Two accessories were used to fix the muscle to be tested, one fixator for the femur and another for fixation of the calcaneus, keeping the knee and ankle with $90^{\circ}$ of angulation. The Tesc ${ }^{\circledR}$ software was used to generate the load versus displacement graph.

The muscle attached to the testing machine was subjected to axial traction with a load of 300 grams for 30 seconds, in order to promote the accommodation of the muscle to the machine. The test was conducted at a speed of $10 \mathrm{~mm} /$ minute and the load applied was registered by the software until the moment of muscle break, the break was considered when there was a $70 \%$ load drop in 10 $\mathrm{mm}$ of stretching. The steps followed for the mechanical test were adapted from the study of Kodama et al. (2012).

The tenacity of the muscles, which is the energy absorption capacity (millijoules) until rupture, was calculated by measuring the area under the load versus displacement curve of each test.

Statistical analysis. The statistical analysis was performed with calculations of mean and standard deviation, after the Shapiro-Wilk normality test confirming the absence of Gaussian distribution, non-parametric tests were applied. To analyze the differences between the variables of the groups, the Kruskal-Wallis test with Dunn's post-test was used. For all analyzes, the level of significance adopted was $5 \%$.

\section{RESULTS}

We analyzed 124 images of Picrosirius, with approximately 25 images per group with 5 images per animal.

Collagen distribution. The images under polarized light show a greater presence of red collagen compared to green in all groups (Fig. 1). In group C, collagen showed a normal distribution between muscle fibers and fascicles, without thickening, with type III collagen in small quantities. The CI group had a greater presence of type I collagen, distributed around blood vessels, around the injured cells and surrounding the inflammatory infiltrate. Type III collagen was more prevalent closer to the focus of inflammation than type I.

The IS group had a similar distribution to the CI group, but there was a greater amount of type I and III collagen, but these were more concentrated than the CI group, which was more dispersed. The IP group had a greater presence of collagen in relation to groups C, CI and IS, the red collagen is distributed around the fibers and on the margins of the inflammatory infiltrate. In the ISP group, there was a greater presence of collagen types I and III, their presence occurred both around the inflamed area and in the middle of the inflammatory infiltrate.

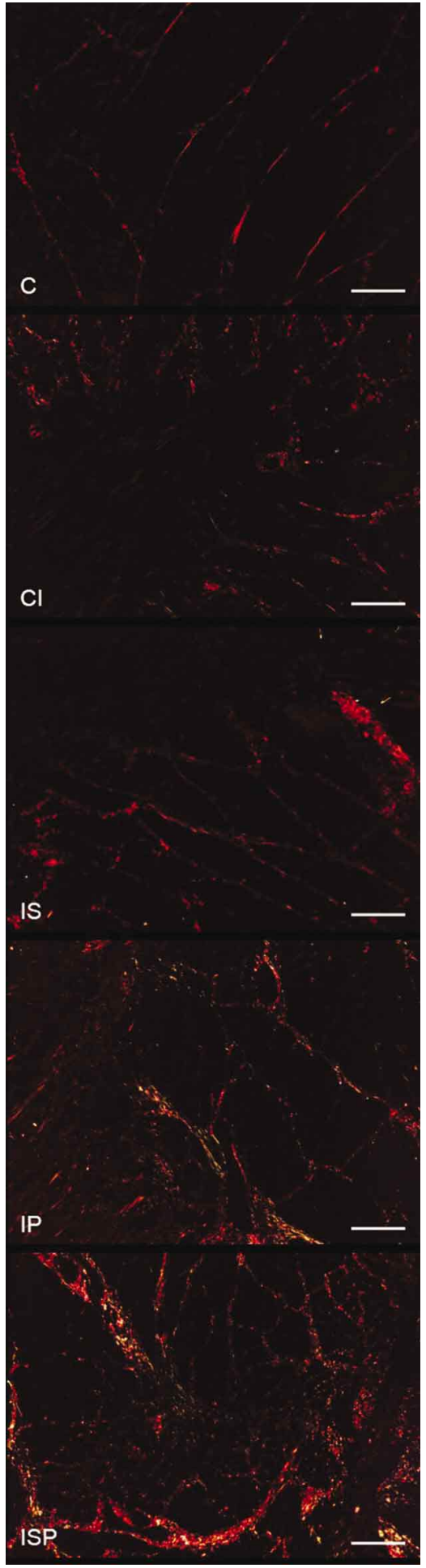

Fig. 1. Images of injured areas stained with picrosirius, the red and green colors are the collagens I and III. Control group (C); Control injury group (CI); Injury suture group (IS); Injury PRP group (IP); Injury suture and PRP group (ISP). Scale bar $=100 \mu \mathrm{m}$. 


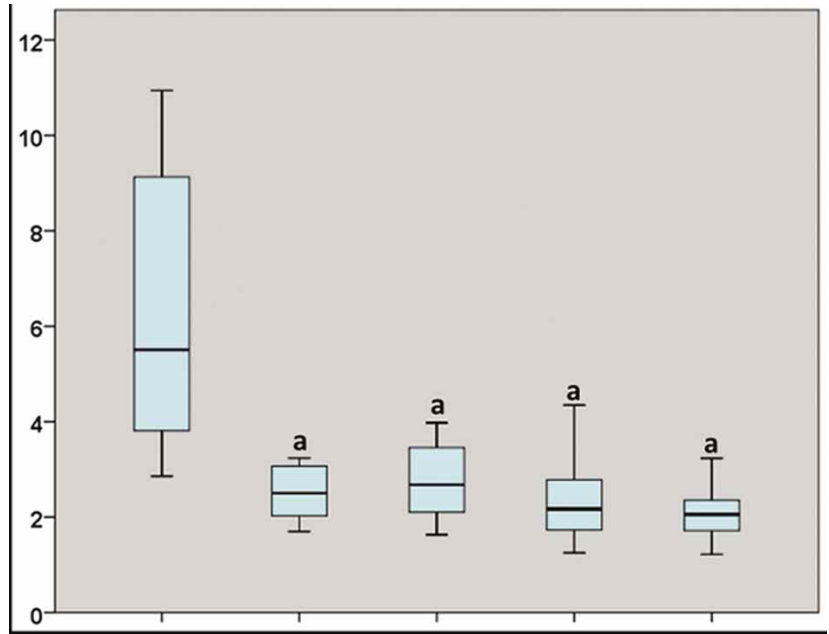

Fig. 2. Relationship between type I and type III collagen. The symbol "a" indicates a significant difference with group C. The unit of measurement is arbitrary units (A.U.).

The relationship between type I and III collagen shows a higher value in group $\mathrm{C}$ compared to group $\mathrm{CI}(\mathrm{p}$ $<0.0001)$, IS ( $\mathrm{p}=0.002)$, IP $(\mathrm{p}<0.0001)$, ISP $(\mathrm{p}<0.0001)$. Although in the injured groups the amount of collagen increased considerably, as seen by histological images, the relationship between them decreased. These results point to a large increase in type III collagen in relation to type I.

The tenacity of the muscles, measured by the mechanical test, showed higher values in group $\mathrm{C}$ compared to the other groups, this difference was significant for the CI groups ( $p<0.0001), \operatorname{IS}(p=0.019), \operatorname{IP}(p=0.007), \operatorname{ISP}(p$ $=0.002$ ). The injured groups showed no difference between them.

\section{DISCUSSION}

In this research, it was observed that muscle injury increased the presence of collagen types I and III in the injured groups, decreased the values of the relationship between collagens as well as reduced the tenacity of all injured muscles. The treatments raised the collagen values (especially the PRP), but with no effect in the muscular tenacity.

The injury inflicted in the gastrocnemius caused deposition of collagen types I and III, this deposition was seen mainly in the injured area where col. I was distributed around the inflammatory infiltrate and between muscle fibers with no sign of the injury while col. III is mainly distributed in the focus of the inflammatory infiltrate and around it.

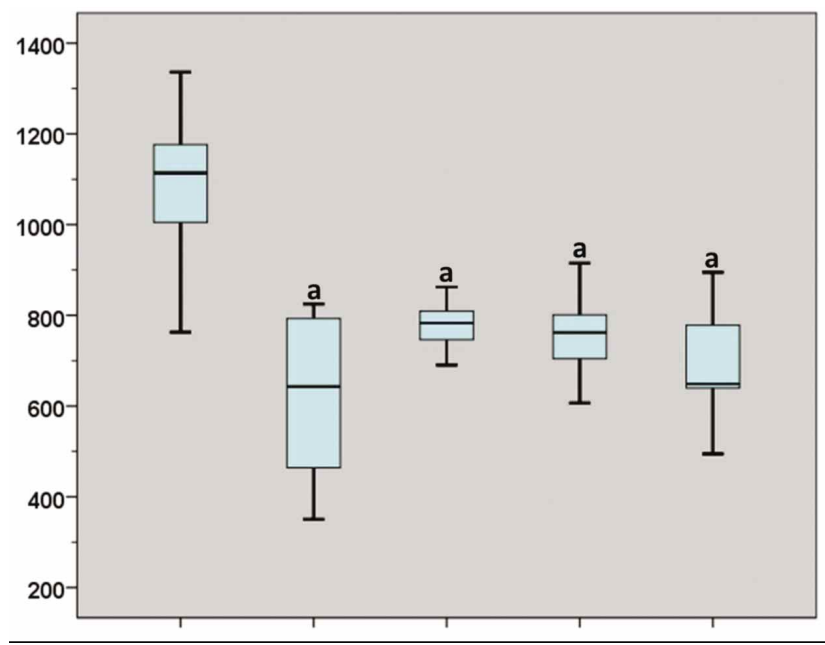

Fig. 3. Boxplot chart with the tenacity values of the groups. The symbol "a" indicates a significant difference with group $\mathrm{C}$. The unit of measurement is millijoules (mj).

Collagen deposition is necessary for correct muscle repair when its fibers are ruptured, a gap is formed and the collagen acts filling and stabilizing this gap (Karalaki et al., 2009). Although the importance of the extracellular matrix during muscle regeneration is already recognized (Mann et al., 2011), it is not known exactly, what role type I and III collagens play at each stage of inflammation. It is believed that initially immature collagen (type III) occupies the injured site, being replaced by mature collagen (type I) after the first days, in the study of Corbiere et al. (2018) the collagen formed in a muscular laceration decreases significantly after the 14 days of the injury. In our study, after seven days, the inflammatory infiltrate remained intense. Thus, it is expected that immature collagen (type III) will continue to be deposited until the beginning of the resorption process or progress to the fibrosis process.

The relationship between collagens had high values in the control group, this proportion was expected in a healthy muscle due to the lower amount of col. III in relation to col. I. The muscle injury decreased the values of the col.I/III ratio, which can be explained by a col. III deposition rate greater than col. I, these same proportions between col. I and III were seen in a similar survey of Lehto et al. (1985).

In addition, lately, similar results were found in the study of Vieira Ramos et al. (2016) where after 7 days of muscle injury, mRNA expression from col. III increased more than col. I. Therefore, at seven days after injury, the deposition of immature collagen (type III) is still more intense than the mature (col. I), indicating that the muscle is not yet stabilized and needs support for the gap formed between the ruptured fibers, which can reduce its resistance 
to external forces. Thus, this large amount of col. III may be responsible for the tenacity values obtained in the mechanical test, which followed the same trend as the relationship between collagens.

The tenacity of the muscles was similar in all injured groups, the treatments applied did not improve the muscle's ability to absorb energy. Figures 2 and 3 show a similarity in the results of the relationship between collagens and muscle tenacity, in both cases the lesion reduced the values without difference with the treatments.

The muscle is composed of contractile and noncontractile structures, the muscle fibers represent most of the muscle and are responsible for the generation of strength, while non-contractile components such as perimysium, epimysium and endomysium they structure and organize the muscle at the same time that transmits the force generated for tendons and bones. In this sense, it is expected that there is a relationship between the non-contractile components (composed mainly of col. I and col. III) and the tenacity, which represents the muscle's ability to absorb energy until breaking completely. Col. III has a great capacity to stretch due to its thin and not very rigid fibers, while col. I have larger, parallel and rigid fibers favoring tensile strength, although its properties are different, the increase in both collagens seen in the histological slides did not alter the muscle's structure. Similar results were observed in the study of Smith \& Barton (2014), in rats with Duchenne dystrophy, where the amount of collagen did not alter muscle stiffness in mechanical tests. In addition, other studies (Lieber \& Ward, 2013; Chapman et al., 2015) pointed that the quantity of collagen crosslinks does not change the stiffness, only its organization in the tissue could do influence its mechanical capacities. This leads us to believe that the collagen seen in the muscles of this research is disorganized and still performs a filling function, instead of structural or repairing of the endomysium, perimysium, and epimysium.

In this way, the present study collaborates with the literature when investigating the use of the two recovery techniques (suture and PRP) in the injured muscle tissue. However, one limitation found was the evaluation of the groups in just one time after the injury, this limitation occurred due to the number of animals available, which prevented us from following the evolution of the measures taken.

\section{CONCLUSION}

We concluded that muscle injury promoted an increase at the injury site, type III collagen in relation to type I and decreased the values of muscle tenacity. In addition, treatments with PRP or suture increased the amount of collagen, but did not interfere with muscle tenacity.

ACKNOWLEDGMENTS. The authors are grateful to the Brazilian Agency of Resources for Higher Education Personnel (CAPES), to the Foundation for Research Support of the State of São Paulo (FAPESP), protocol number 2017/ 06930-0 and the Universidade do Oeste Paulista (Unoeste), for supporting the development of this study.

GARCIA, T. A.; OZAKI, G. A. T.; CASTOLDI, R. C.; JOB, A. E.; CAMARGO, R. C. T.; FILHO, J. C. S. C. \& BELANGERO, W. D. Relaciones de colágeno I y III y tenacidad del músculo de las ratas lesionadas y tratadas con plasma rico en plaquetas. Int J. Morphol., 38(5):1392-1397, 2020.

RESUMEN : Las lesiones musculares graves son comunes durante los accidentes y la integridad del músculo está sujeta a una larga recuperación. En esos casos la cirugía, para la sutura del músculo, es el tratamiento común, no obstante el plasma rico en plaquetas (PRP) ha sido utilizado recientemente en lesiones ortopédicas, debido a sus factores del crecimiento. El objetivo del estudio fue analizar la asociación de las técnicas de sutura y PRP en la histología y tenacidad de músculo lesionado. Fueron utilizadas 70 ratas distribuidas en cinco grupos: control (C), control lesión (CL), lesión y sutura (LS), lesión y PRP (LPRP), lesión, sutura y PRP (LSPRP). Aproximadamente en la lesión, el $50 \%$ de la longitud y el $100 \%$ del espesor del músculo gastrocnemio fueron seccionados. El PRP homólogo fue aplicado 24 horas después de la lesión. En el $7^{\circ}$ día después de la lesión los animales fueron eutanasiados y las muestras fueran sometidas al ensayo mecánico para la medición de la tenacidad y análisis del colágeno, para realizar el cálculo de la relación entre los colágenos I y III. Los resultados demostraron una reducción significativa $(p<0,05)$ en los valores de la relación entre los colágenos en todos los grupos lesionados en relación al grupo C. La tenacidad fue $(p<0,05)$ reducida significativamente en los grupos lesionados en relación al grupo control, sin diferencia entre los tratados. En la lesión muscular hubo disminución de los valores de colágeno, aunque en los tratamientos se observó elevación de la cantidad de colágeno en la área lesionada, esta no tuvo efecto en la tenacidad de los músculos que fue disminuida en la lesión.

PALABRAS CLAVE: Lesión muscular; Plasma-rico en plaquetas; Sutura; Colágeno.

\section{REFERENCES}

Andia, I. \& Abate, M. Platelet-rich plasma in the treatment of skeletal muscle injuries. Expert Opin. Biol. Ther., 15(7):987-99, 2015.

Chapman, M. A.; Pichika, R. \& Lieber, R. L. Collagen crosslinking does not dictate stiffness in a transgenic mouse model of skeletal muscle fibrosis. J. Biomech., 48(2):375-8, 2015. 
Cole, B. J.; Seroyer, S. T.; Filardo, G.; Bajaj, S. \& Fortier, L. A. Plateletrich plasma: Where are we now and where are we going? Sports Health, 2(3):203-10, 2010.

Corbiere, T. F.; Weinheimer-Haus, E. M.; Judex, S. \& Koh, T. J. Lowintensity vibration improves muscle healing in a mouse model of laceration injury. J. Funct. Morphol. Kinesiol., 3(1):1, 2018.

Dimauro, I.; Grasso, L.; Fittipaldi, S.; Fantini, C.; Mercatelli, N.; Racca, S.; Geuna, S.; Di Gianfrancesco, A.; Caporossi, D.; Pigozzi, F.; et al. Platelet-rich plasma and skeletal muscle healing: a molecular analysis of the early phases of the regeneration process in an experimental animal model. PLoS One, 9(7):e102993, 2014.

Fernandes, T. L.; Pedrinelli, A. \& Hernandez, A. J. Muscle injury Physiopathology, diagnosis, treatment and clinical presentation. Rev. Bras. Ortop., 46(3):247-55, 2015.

Hamid, M. S. A.; Yusof, A. \& Mohamed Ali, M. R. Platelet-rich plasma (PRP) for acute muscle injury: a systematic review. PLoS One, 9(2):e90538, 2014.

Hammond, J. W.; Hinton, R. Y.; Curl, L. A.; Muriel, J. M. \& Lovering, R. M. Use of autologous platelet-rich plasma to treat muscle strain injuries. Am. J. Sports Med., 37(6):1135-42, 2009.

He, M.; Sebastin, S. J.; Gan, A. W. T.; Lim, A. Y. T. \& Chong, A. K. S. Biomechanical comparison of different suturing techniques in rabbit medial gastrocnemius muscle laceration repair. Ann. Plast. Surg., 73(3):333-5, 2014.

Horst, K.; Dienstknecht, T.; Sellei, R. M. \& Pape, H. C. Partial rupture of the hamstring muscle complex: a literature review on treatment options. Eur. J. Orthop. Surg. Traumatol., 24(3):285-9, 2014.

Hwang, J. H.; Ra, Y. J.; Lee, K. M.; Lee, J. Y. \& Ghil, S. H. Therapeutic effect of passive mobilization exercise on improvement of muscle regeneration and prevention of fibrosis after laceration injury of rat. Arch. Phys. Med. Rehabil., 87(1):20-6, 2006.

Karalaki, M.; Fili, S.; Philippou, A. \& Koutsilieris, M. Muscle regeneration: cellular and molecular events. In Vivo, 23(5):779-96, 2009.

Kodama, F. Y.; Camargo, R. C. T.; Job, A. E.; Ozaki, G. A. T.; Koike, T. E. \& Camargo Filho, J. C. S. Propriedades mecânicas do músculo de ratos adultos e idosos, exercitado pós-imobilização. Acta Ortop. Bras., 20(4):218-22, 2012.

Lehto, M.; Sims, T. J. \& Bailey, A. J. Skeletal muscle injury--Molecular changes in the collagen during healing. Res. Exp. Med. (Berl.), 185(2):95-106, 1985.

Li, W.; Enomoto, M.; Ukegawa, M.; Hirai, T.; Sotome, S.; Wakabayashi, Y.; Shinomiya, K. \& Okawa, A. Subcutaneous injections of plateletrich plasma into skin flaps modulate proangiogenic gene expression and improve survival rates. Plast. Reconstr. Surg., 129(4):858-66, 2012.

Lieber, R. L. \& Ward, S. R. Cellular mechanisms of tissue fibrosis. 4. Structural and functional consequences of skeletal muscle fibrosis. Am. J. Physiol. Cell Physiol., 305(3):C241-52, 2013.

Mann, C. J.; Perdiguero, E.; Kharraz, Y.; Aguilar, S.; Pessina, P.; Serrano, A. L. \& Muñoz-Cánoves, P. Aberrant repair and fibrosis development in skeletal muscle. Skelet. Muscle, 1(1):21, 2011.

Mescher, A. L. Junqueira's Basic Histology. Text and Atlas. $13^{\text {th }}$ ed. New York, McGraw-Hill Education, 2013.

Moraes, V. Y.; Lenza, M.; Tamaoki, M. J.; Faloppa, F. \& Belloti, J. C. Platelet-rich therapies for musculoskeletal soft tissue injuries. Cochrane Database Syst. Rev., (12):CD010071, 2013.

Ramos, L. A.; de Carvalho, R. T.; Abdalla, R. J. \& Ingham, S. J. M. Surgical treatment for muscle injuries. Curr. Rev. Musculoskelet. Med., 8(2):18892, 2015.

Rui, P.; Kang, K. \& Albert, M. National Hospital Ambulatory Medical Care Survey: 2013 Emergency Department Summary Tables. Atlanta, Centers for Disease Control and Prevention, 2013. Available from: http://www.cdc.gov/nchs/data/ahcd/nhamcs_emergency/ 2013_ed_web_tables.pdf.

Sánchez-González, D. J.; Méndez-Bolaina, E. \& Trejo-Bahena, N. I. Platelet-rich plasma peptides: key for regeneration. Int. J. Pept., 2012:532519, 2012.
Smith, L. R. \& Barton, E. R. Collagen content does not alter the passive mechanical properties of fibrotic skeletal muscle in Mdx mice. Am. $J$. Physiol. Cell Physiol., 306(10):C889-98, 2014.

Vieira Ramos, G.; Pinheiro, C. M.; Messa, S. P.; Delfino, G. B.; Marqueti, R. de C.; Salvini, T. de F. \& Durigan, J. L. Q. Cryotherapy reduces inflammatory response without altering muscle regeneration process and extracellular matrix remodeling of rat muscle. Sci. Rep., 6:18525, 2016.

Willits, K.; Kaniki, N. \& Bryant, D. The use of platelet-rich plasma in orthopedic injuries. Sports Med. Arthrosc. Rev., 21(4):225-30, 2013.

\author{
Corresponding author: \\ Thiago Alves Garcia \\ Rua Roberto Simonsen, 305 \\ Centro Educacional - P. Prudente/SP \\ CEP 19060-900 \\ São Paulo \\ BRAZIL
}

Email: t207409@dac.unicamp.br

Received: 13-04-2020

Accepted: 17-05-2020 